\title{
Pharmacokinetic/Pharmacodynamic Analysis of Tacrolimus-Induced QT Prolongation in Guinea Pigs
}

\author{
Tsuyoshi Minematsu, Hisakazu Ohtani, Hitoshi Sato, ${ }^{*}$ and Tatsuji Iga \\ Department of Pharmacy, University of Tokyo Hospital, Faculty of Medicine, University of Tokyo, 7-3-1 Hongo, Bunkyo- \\ ku, Tokyo 113-8655, Japan. Received June 10, 1999; accepted August 18, 1999
}

\begin{abstract}
Recently, several reports of clinical cases of QT prolongation and torsades de pointes, associated with the use of tacrolimus (FK506), have come to light. We have previously demonstrated FK506-induced QT prolongation in guinea pigs [Minematsu T., et al., Life Sci., 65, PL197-PL202 (1999)]. We now examined the relationship between QTc prolongation and the pharmacokinetics of FK506 in guinea pigs, in order to evaluate the arrhythmogenicity of FK506 when compared with that of quinidine sulfate (QND). Thus, dose-response relationships for FK506 $(0.01$ or $0.1 \mathrm{mg} / \mathrm{h} / \mathrm{kg})$ or QND $(30 \mathrm{mg} / \mathrm{h} / \mathrm{kg})$ were investigated during and after intravenous infusion and also following intravenous bolus administration of FK506 $(0.2 \mathrm{mg} / \mathrm{kg})$. The dose-response relationship between plasma drug concentration and QTe prolongation for FK506 and QND were subsequently analyzed using an effect compartment model. The pharmacodynamic parameters thus obtained were as follows: $k_{\mathrm{E} 0} 2.72 \times 10^{-4}$ $\left(\mathrm{min}^{-1}\right), E_{\max } 27.1(\mathrm{~ms}), \mathrm{EC}_{50} 0.376(\mathrm{ng} / \mathrm{ml})$ for FK506; and $k_{\mathrm{E} 0} 0.148\left(\mathrm{~min}^{-1}\right), K 8.41(\mathrm{~ms} \cdot \mathrm{ml} / \mu \mathrm{g})$ for QND. The anti-clockwise hysteresis observed for FK506-induced QT prolongation was successfully analyzed by the present pharmacokinetic/pharmacodynamic model, which may provide a rational basis for developing a clinical dosing regimen to avoid possible QT prolongation induced by FK506.
\end{abstract}

Key words tacrolimus; quinidine; QT prolongation; electrocardiogram; arrhythmia; pharmacodynamic

Tacrolimus (FK506), a potent immunosuppressant widely used in organ transplantation, ${ }^{1)}$ is currently undergoing clinical trials for use in the treatment of autoimmune diseases. ${ }^{2}$ However, recent reports ${ }^{3-6)}$ suggest that FK506 is cardiotoxic. Especially, clinical cases of torsades de pointes and QT prolongation have been reported following treatment with FK506. ${ }^{78)}$ We recently reported that FK506 prolonged the QT interval in guinea pigs, and that there was an anticlockwise hysteresis effect related to whole blood FK506 concentration. ${ }^{9 y}$ However, quantitative analysis of FK506-induced QT prolongation has so far not been reported, thus the present study serves to address this issue.

Previously, in order to quantitatively estimate the risk of drug-induced QT prolongation, we have examined the pharmacokinetic-pharmacodynamic (PK/PD) relationship between drug concentration and QT prolongation in small experimental animals using various therapeutic agents. ${ }^{10-14)}$ Thus, in the present study we have performed a PK/PD analysis of FK506-induced QT prolongation in guinea pigs, using an effect compartment model. ${ }^{15)}$ As a positive control, we employed quinidine sulfate (QND), which has been attributed as the primary cause of drug-induced torsades de pointes in humans. ${ }^{16)}$

\section{MATERIALS AND METHODS}

Animals Male Hartley guinea pigs weighing $360-500 \mathrm{~g}$ were purchased from Nihon Ikagaku Dobutsu Shizai Kenkyusho (Tokyo, Japan) and kept with free access to food and water.

Materials FK506, as a solution, Prograf $^{\circledR}$ injection, $5 \mathrm{mg} / \mathrm{ml}$ ) and QND, in powder form, were purchased from Fujisawa Pharmaceutical (Osaka, Japan) and Wako Pure Chemical Industries (Osaka, Japan), respectively. All other chemicals used were of reagent grade.

In Vitro Blood-to-Plasma Concentration Ratio of FK506 Initially the relationship between whole blood and

* To whom correspondence should be addressed. plasma concentrations of FK506, which is known to be nonlinear ${ }^{17)}$ in humans, ${ }^{18)}$ rats, ${ }^{19)}$ and rabbits, ${ }^{20,21)}$ was established, in order to permit estimation of the plasma concentration of FK506 from the data for in vivo whole blood concentrations. Guinea pigs were anesthetized with a combination of urethane and $\alpha$-chloralose $(1.2 \mathrm{mg} / \mathrm{kg}$ and $30 \mathrm{mg} / \mathrm{kg}$ i.p., respectively). Subsequently, blood was collected from the carotid artery and EDTA $2 \mathrm{Na}$ was added at $1 \mathrm{mg} / \mathrm{ml}$ of whole blood. An aliquot of the collected blood was centrifuged at $4000 \times g$ for $4 \mathrm{~min}$ to determine the hematocrit value $(H t)$. Subsequently, after preincubation for $3 \mathrm{~min}$ at $37^{\circ} \mathrm{C}$, aliquots of the collected blood $(990 \mu \mathrm{l})$ were spiked with $10 \mu \mathrm{l}$ of FK506, yielding whole blood FK506 concentrations of 12.5, $25,50,100,200,400$, and $800 \mathrm{ng} / \mathrm{ml}$. Following this, the spiked blood samples were incubated for $30 \mathrm{~min}$ at $37^{\circ} \mathrm{C}$. Plasma and blood cells were then separated by centrifugation at $37^{\circ} \mathrm{C}$ for $4 \mathrm{~min}$ at $1000 \times \mathbf{g}$. Finally, the concentration of FK506 in both whole blood and plasma in each aliquot was determined, using a microparticle enzyme immunoassay (MEIA), as previously reported. ${ }^{9)}$ At steady state, the relationship between $H t$ and the concentrations of FK506 in whole blood $\left(C_{\mathrm{WB}}\right)$, and plasma $\left(C_{\mathrm{p}}\right)$ can be expressed as follows ${ }^{20)}$ :

$$
C_{\mathrm{WB}}=C_{\mathrm{p}}+H t \cdot \frac{B_{\max } \cdot C_{\mathrm{P}}}{K_{\mathrm{d}}+C_{\mathrm{P}}}
$$

where $B_{\max }$ is the binding capacity, and $K_{\mathrm{d}}$ is the affinity constant. These parameters were obtained by fitting the observed data to Eq. (1) using a nonlinear least-squares regression program (MULTI). ${ }^{22)}$

Pharmacokinetic Experiments Data from infusion experiments for whole blood FK506 concentrations and plasma QND concentrations were derived from our previous study.9) For studies on the intravenous bolus administration of FK506, guinea pigs were anesthetized in the same manner described above, and restrained in a supine position. The trachea, right jugular vein, and right carotid artery were then

(C) 1999 Pharmaceutical Society of Japan 
cannulated with polyethylene tubing. A body temperature at $37.5 \pm 0.5^{\circ} \mathrm{C}$ was maintained throughout the experiment. FK506 $(0.2 \mathrm{mg} / \mathrm{kg})$ was intravenously administered, through the jugular vein, as a diluted solution of $0.2 \mathrm{mg} / \mathrm{ml} \mathrm{FK506} \mathrm{in}$ a physiological salt solution $\left(\mathrm{NaCl} 135 \mathrm{~mm}, \mathrm{NaHCO}_{3} 11.9\right.$ $\mathrm{mm}, \mathrm{KCl} 5.4 \mathrm{~mm}, \mathrm{CaCl}_{2} 1.8 \mathrm{~mm}, \mathrm{MgCl}_{2} 1.0 \mathrm{~mm}$ ). Blood samples of $300 \mu \mathrm{l}$ were collected from the carotid artery at 2, 5, $15,30,60,120,180$, and $240 \mathrm{~min}$ for the bolus administration study, and a whole blood concentration of FK506 was subsequently determined by the MEIA method. In addition, plasma potassium concentrations were determined by the atomic absorption method, previously described by Hirota et $a .^{12)}$

Pharmacodynamic Experiments Data from infusion experiments for FK506- and QND-induced QT prolongation were derived from our previous study. ${ }^{9)}$ In the intravenous bolus administration study, pharmacodynamic experiments were performed, without blood sampling, on groups of animals different from those used in the pharmacokinetic experiments, but using identical conditions. The electrocardiogram (ECG) was recorded and analyzed as previously described by Ohtani et al ${ }^{10)}$ Briefly, signals from the bipolar lead II were amplified by means of an electric amplifier (AB-621G, Nihon-Koden, Tokyo, Japan), stored in a personal computer (PC-9801VX, NEC, Tokyo, Japan) via an A/D converter (Analog-Pro Jr., Canopus Electric, Kobe, Japan) and analyzed using WAVE MASTER II software (Canopus Electric, Kobe, Japan). ECG parameters were derived from the average wave shape of $10 \mathrm{~s}$ recordings. For the determination of QT prolongation, we exploited the change in QTc intervals (i.e. QT intervals corrected by Bazett's formula ${ }^{23)}$ ) since, in the case of guinea pig ECGs, QT intervals have been reported to be affected by heart rates. ${ }^{24)}$

Pharmacokinetic Analysis In the case of FK506, a 3compartment model, which assumes rapidly equilibrating but saturable intra-blood-cellular binding (Fig. 1), was employed to enable analysis of the time profile of whole blood FK506 concentration. In the 3-compartment model, the following equations were indicated:

Infusion study ( $I=0$ after $90 \mathrm{~min}$ ),

$$
\begin{aligned}
& \frac{d C_{1}}{d t}=\frac{I}{V_{1}}+k_{12} \cdot\left(C_{2}-C_{1}\right)+k_{13} \cdot\left(C_{3 \mathrm{u}}-C_{1}\right)-k_{10} \cdot C_{1}, \quad C_{1}(0)=0 \\
& \frac{d C_{2}}{d t}=k_{12} \cdot\left(C_{1}-C_{2}\right), \quad C_{2}(0)=0 \\
& \frac{d C_{3}}{d t}=k_{31} \cdot\left(C_{1}-C_{3 \mathrm{u}}\right), \quad C_{3}(0)=0 \\
& C_{3 \mathrm{u}}=\frac{-\left(K_{\mathrm{d}}+B_{\max }-C_{3}\right)+\sqrt{\left(K_{\mathrm{d}}+B_{\max }-C_{3}\right)^{2}+4 \cdot K_{\mathrm{d}} \cdot C_{3}}}{2} \\
& C_{\mathrm{WB}}=(1-H t) \cdot C_{1}+H t \cdot C_{3}
\end{aligned}
$$

where $t$ is time after drug administration; $C_{1}, C_{2}$, and $C_{3}$ are FK506 concentrations in the central compartment, peripheral compartment, and blood cell compartment, respectively; $C_{1}(0), C_{2}(0)$, and $C_{3}(0)$ are $C_{1}, C_{2}$, and $C_{3}$ before the start of drug administration, respectively; $C_{3 \mathrm{u}}$ is the unbound FK506 concentration in blood cell compartment; $k_{10}, k_{12}, k_{21}, k_{13}$, and $k_{31}$ are rate constants; $V_{1}$ is the distribution volume of the central compartment; and $I$ is an infusion rate. The above equations were obtained by reducing the distribution volume

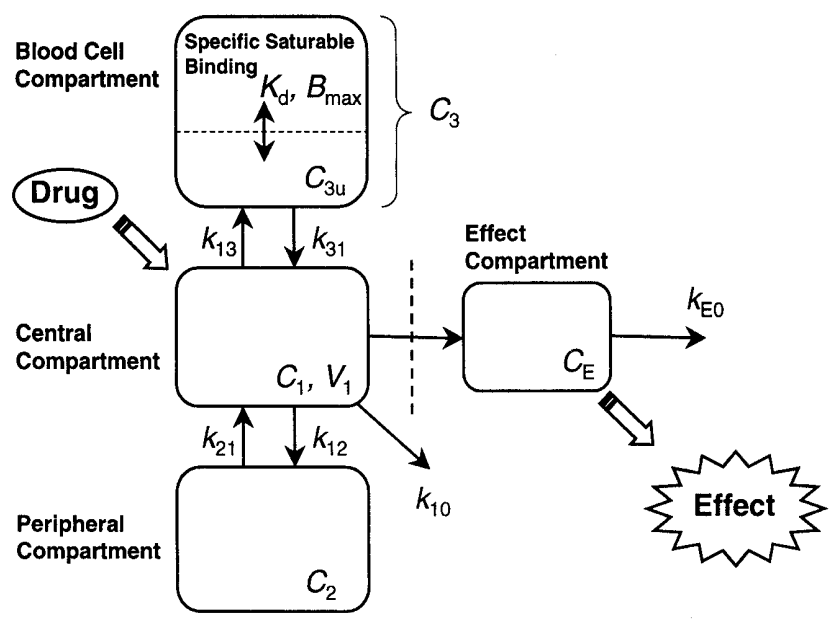

Fig. 1. PK/PD Model Applied to FK506-Induced QT Prolongation

See text for abbreviations. A bidirectional arrow denotes instantaneous equilibrium, and a single directional solid arrow denotes a non-instantaneous equilibrium process.

of the peripheral compartment and blood cell compartment with equations, i.e. $k_{12} \cdot V_{1}=k_{21} \cdot V_{2}, k_{13} \cdot V_{1}=k_{31} \cdot V_{3}$ :

Bolus study,

$$
\frac{d C_{1}}{d t}=k_{12} \cdot\left(C_{2}-C_{1}\right)+k_{13} \cdot\left(C_{3 \mathrm{u}}-C_{1}\right)-k_{10} \cdot C_{1}, \quad C_{1}(0)=\frac{\text { Dose }}{V_{1}}
$$

Other equations for $d C_{2} / d t, d C_{3} / d t, C_{3 \mathrm{u}}$, and $C_{\mathrm{WB}}$ are the same as Eqs. (2-2), (2-3), (2-4), and (2-5), respectively. The parameters of $k_{10}, k_{12}, k_{21}, k_{13}, k_{31}$, and $V_{1}$ were obtained by simultaneous fitting of the infusion and bolus data to the above pharmacokinetic model using the MLAB computer program (Civilized Software, Inc., Bethesda, U.S.A.). In the case of QND, a 2-compartment open model was employed to enable analysis of the time profile of plasma QND concentration. Pharmacokinetic parameters were obtained by fitting of the observed data to the pharmacokinetic model using MLAB.

PK/PD Analysis of QTc Prolongation The effect of a given drug at each time-point was expressed in terms of the change from the value prior to drug administration. The plasma concentration at each time-point, employed here as the input function, was the value calculated from the pharmacokinetic parameters obtained above. Pharmacodynamic analyses of FK506 and QND were conducted using the effect compartment model (Fig. 1), ${ }^{15)}$ as delays in QTc prolongation were observed for both drugs. The drug concentration in the effect compartment $\left(C_{\mathrm{E}}\right)$ is described by Eq. (4):

$$
\frac{d C_{\mathrm{E}}}{d t}=k_{\mathrm{E} 0} \cdot\left(C_{1}-C_{\mathrm{E}}\right)
$$

where $k_{\mathrm{E} 0}$ denotes the elimination rate constant from the effect compartment.

In the case of FK506, the $E_{\max }$ model described by the following differential equation was employed to relate $C_{\mathrm{E}}$ to the effect $(E)$, since a saturation of the effect with respect to $C_{\mathrm{E}}$ was observed:

$$
\frac{d E}{d t}=\frac{E C_{50} \cdot E_{\max }}{\left(E C_{50}+C_{\mathrm{E}}\right)^{2}} \cdot \frac{d C_{\mathrm{E}}}{d t}
$$

where $E_{\max }$ and $E C_{50}$ are the maximal effect and the concentration which gives the half-maximal effect, respectively. The pharmacodynamic parameters of $k_{\mathrm{E} 0}, E_{\max }$, and $E C_{50}$ were 
obtained by simultaneous fitting of the infusion and bolus data to Eqs. (4) and (5), using MLAB.

The effect compartment model was also applied to QND. However, in this case a linear relationship between $E$ and $C_{\mathrm{E}}$ as described by Eq. (6) was applied, since the $E_{\max }$ model failed to satisfactorily describe this relationship:

$$
\frac{d E}{d t}=K \cdot \frac{d C_{E}}{d t}
$$

where $K$ is a slope constant. The pharmacodynamic parameters of $k_{\mathrm{E} 0}$ and $K$ were obtained by fitting the observed data to Eqs. (4) and (6), using MLAB.

\section{RESULTS}

The Blood-to-Plasma Concentration Ratio for FK506

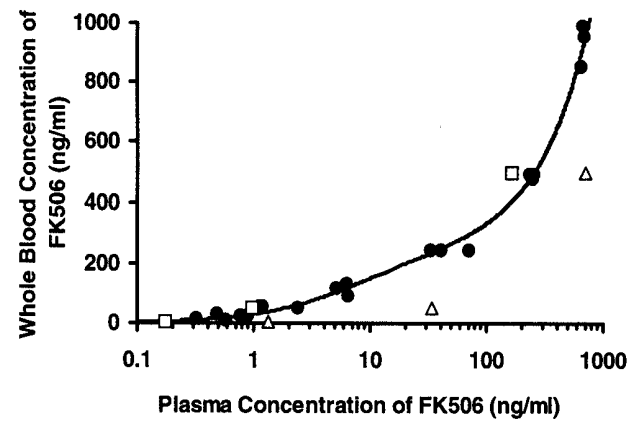

Fig. 2. In Vitro Assay of the Relationship between Plasma FK506 Concentration and Whole Blood FK506 Concentration in Guinea Pigs (๑), Rats $(\triangle)$, and Humans $(\square)$

Data for rats and humans were derived from previous studies. ${ }^{18,19)}$ The line represents a best-fit of the data to Eq. (1)

(A) Infusion (Whole Blood)

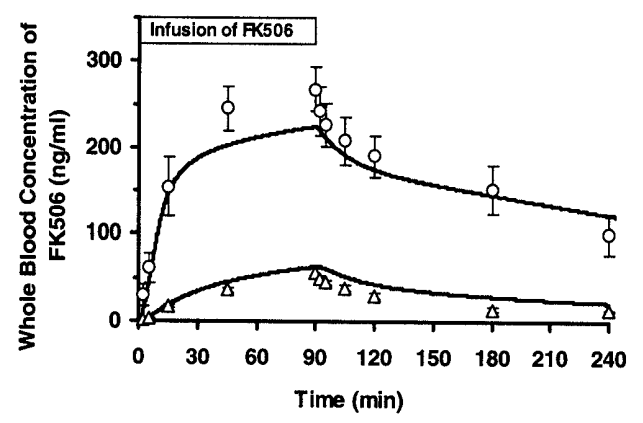

(B) Bolus (Whole Blood)

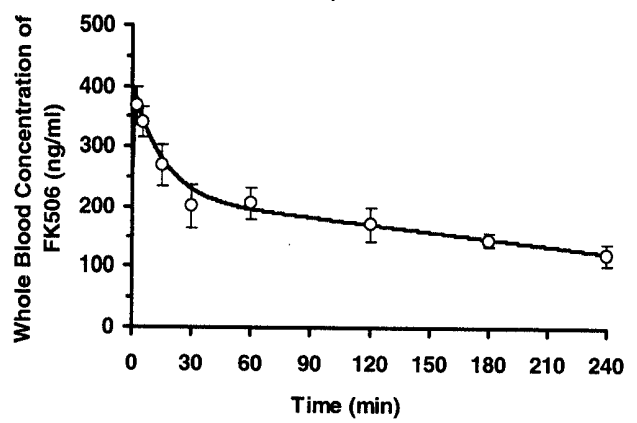

The relationship between whole blood and plasma concentrations of FK506 showed a nonlinear profile (Fig. 2), probably as a result of a saturable distribution property of FK506 into blood cells. $H t$ was found to be 0.452 and the values of $B_{\max }$ and $K_{\mathrm{d}}$ were estimated to be $556 \pm 20 \mathrm{ng} / \mathrm{ml}$ and $7.85 \pm 1.73$ $\mathrm{ng} / \mathrm{ml}$, respectively (estimate \pm S.D.).

Pharmacokinetics of FK506 and QND in Guinea Pigs Figures $3 \mathrm{~A}$ and $3 \mathrm{~B}$ illustrate whole blood concentrations of FK506 with respect to time after infusion and bolus administration, respectively. Figures $3 \mathrm{C}$ and $3 \mathrm{D}$ represent the time courses of simulated plasma concentrations of FK506 $\left(C_{1}\right)$, with respect to time after infusion and bolus administration, respectively. The pharmacokinetic parameters were presented in Table 1. In the FK506 bolus study, no significant change in plasma potassium concentration was observed, i.e. 3.46士 $0.40 \mathrm{mEq}$ (mean \pm S.E.M.), before drug administration compared to $3.49 \pm 0.44 \mathrm{mEq}$ at $240 \mathrm{~min}$ after administration $(n=6)$. The time course of plasma QND concentration was accurately predicted by the 2-compartment open model (Fig. 4 and Table 1).

Pharmacodynamics of QT Prolongation by FK506 An administration rate-dependent increase in the QTc interval was observed during the constant intravenous infusion of FK506 (Fig. 5A). Prolongation of the QTc interval persisted until $150 \mathrm{~min}$ after termination of the infusion. Similarly, following intravenous bolus administration of FK506, prolongation of the QTc interval also persisted, for as long as $240 \mathrm{~min}$ after administration (Fig. 5B). The relationship between the plasma concentration of FK506 and the change in QTc interval after infusion showed an anti-clockwise hysteresis (Fig. 6).

Pharmacodynamics of QT Prolongation by QND In

(C) Infusion (Plasma)

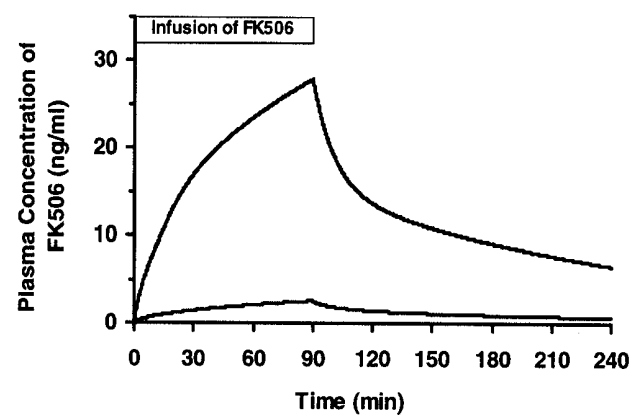

(D) Bolus (Plasma)

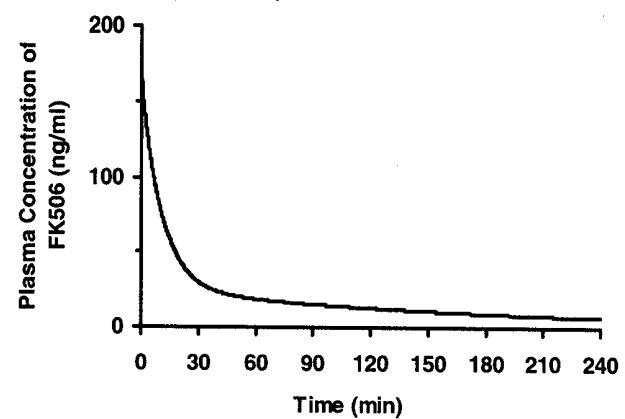

Fig. 3. Time Courses of Blood FK506 Concentration in Guinea Pigs

A. Whole blood concentrations of FK506 during and after intravenous FK506 infusion at $0.01 \mathrm{mg} / \mathrm{h} / \mathrm{kg}(\triangle), 0.1 \mathrm{mg} / \mathrm{h} / \mathrm{kg}(O)$. B. Whole blood concentrations of FK506 after intravenous bolus administration of FK506 $(0.2 \mathrm{mg} / \mathrm{kg})$. C. Calculated plasma concentrations of FK506 during and after intravenous FK506 infusion at $0.01 \mathrm{mg} / \mathrm{h} / \mathrm{kg}$, and 0.1 $\mathrm{mg} / \mathrm{h} / \mathrm{kg}$. D. Calculated plasma concentrations of FK506 after intravenous bolus administration of FK506 $(0.2 \mathrm{mg} / \mathrm{kg})$. Data are expressed as the mean \pm S.E.M. of 5 animals. A best-fit line to a 3-compartment model is shown for each graph. Data for whole blood FK506 concentrations in the infusion study were derived from Ref. 9. 
Table 1. Pharmacokinetic Parameters of FK506 and QND in Guinea Pigs

\begin{tabular}{ccc}
\hline \hline Parameters & FK506 & QND \\
\hline$k_{10}\left(\mathrm{~min}^{-1}\right)$ & $0.0285[0.0245,0.0325]$ & $0.152[0.099,0.205]$ \\
$k_{12}\left(\mathrm{~min}^{-1}\right)$ & $0.0523[0.0513,0.0533]$ & $0.431[0.384,0.478]$ \\
$k_{21}\left(\mathrm{~min}^{-1}\right)$ & $0.019[0.0137,0.0243]$ & $0.0142[0.0107,0.0177]$ \\
$k_{13}\left(\mathrm{~min}^{-1}\right)$ & $0.0931[0.0662,0.110]$ & - \\
$k_{31}\left(\mathrm{~min}^{-1}\right)$ & $7.46[5.85,9.07]$ & - \\
$V_{1}(\mathrm{ml} / \mathrm{kg})$ & $1140[1060,1220]$ & $239[218,260]$ \\
\hline
\end{tabular}

See text for abbreviations. Parameters were obtained by fitting the data for drug concentrations to each pharmacokinetic model. Values are expressed as the estimate [ $68 \%$ confidence interval]

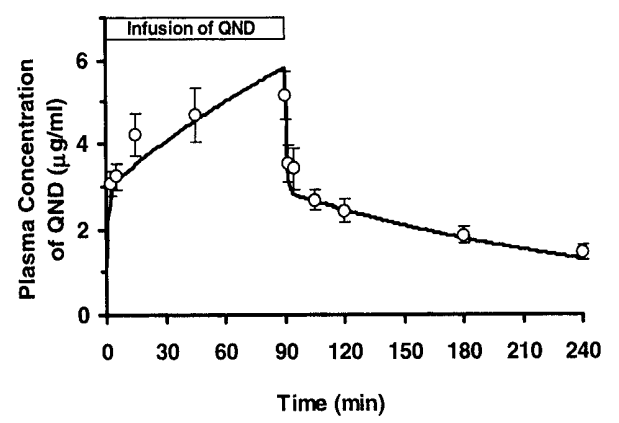

Fig. 4. Time Course of Plasma Concentration of QND in Guinea Pigs during and after Intravenous Infusion of QND at $30 \mathrm{mg} / \mathrm{h} / \mathrm{kg}(O)$

Data are expressed as the mean \pm S.E.M. of 5 animals. A best-fit line to a 2-compartment open model is shown. Data for plasma QND concentrations were derived from Ref. 9.

\section{(A) Infusion}

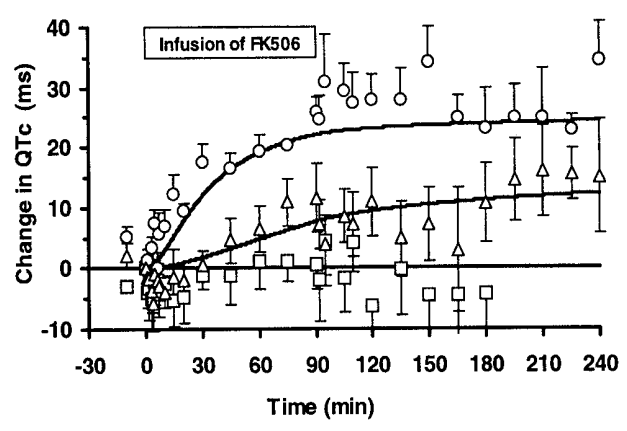

\section{(B) Bolus}

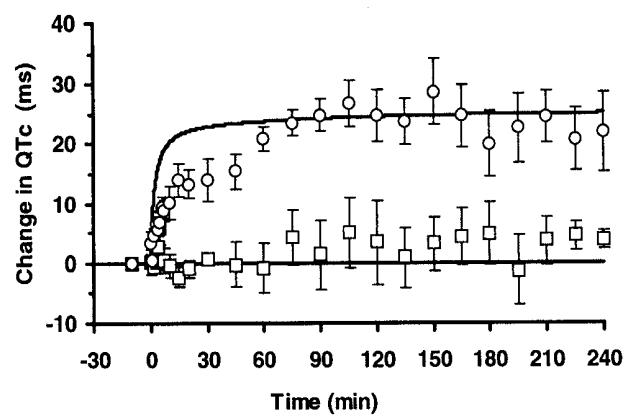

Fig. 5. Time Courses of the Change in QTc Interval in Guinea Pigs after Administation of FK506

A. The change in QTc interval during and after intravenous infusion of vehicle $(\square)$ FK506 at $0.01 \mathrm{mg} / \mathrm{h} / \mathrm{kg}(\triangle)$, and FK506 at $0.1 \mathrm{mg} / \mathrm{h} / \mathrm{kg}(\bigcirc)$. B. The change in QTc interval after intravenous bolus administration of vehicle $(\square)$, and FK506 $(0.2 \mathrm{mg} / \mathrm{kg}$ ) (O). Data are expressed as the mean \pm S.E.M. of $4-5$ animals. A best-fit line to the effect compartment model is shown for each graph. Some of the data were derived from Ref. 9.

\section{(A) Infusion}

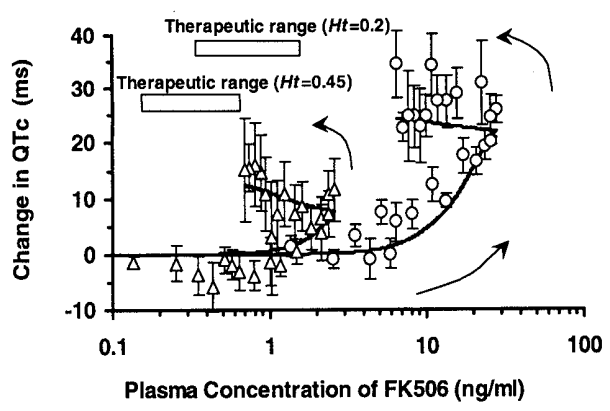

(B) Bolus

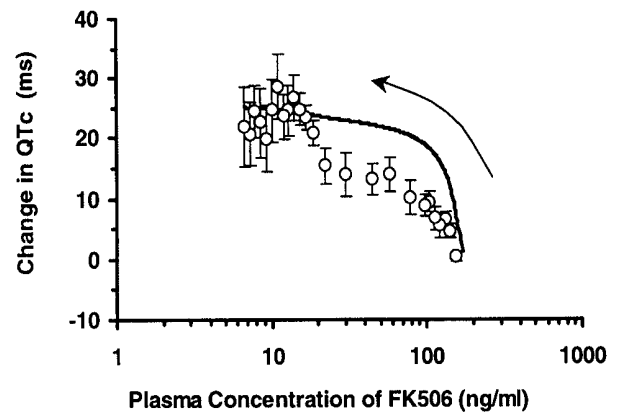

Fig. 6. Relationship between the Plasma FK506 Concentration and the Change in QTc Interval in Guinea Pigs

A. Intravenous infusion of FK506 at $0.01 \mathrm{mg} / \mathrm{h} / \mathrm{kg}(\triangle)$, and $0.1 \mathrm{mg} / \mathrm{h} / \mathrm{kg}(O)$. B. Intravenous bolus administration of FK506 $(0.2 \mathrm{mg} / \mathrm{kg})$. Data are expressed as the mean \pm S.E.M. of 5 animals. The therapeutic ranges for plasma FK506 concentration, corresponding to a whole blood FK506 concentration range of $5-20 \mathrm{ng} / \mathrm{ml}$, were calculated using Eq. 1. Each arrow indicates an elapse of time. A best-fit line to the effect compartment model is shown for each graph. Some of the data were derived from Ref. 9.

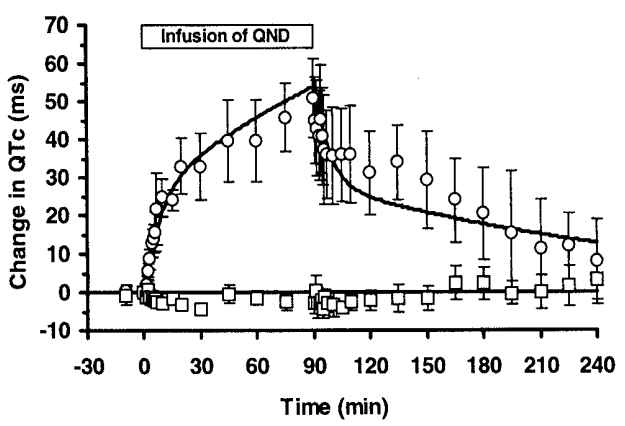

Fig. 7. Time Courses of the Change in QTc Interval in Guinea Pigs during and after Intravenous Infusion of Vehicle $(\square)$ and QND at $30 \mathrm{mg} / \mathrm{h} / \mathrm{kg}(\mathrm{O})$

Data are expressed as the mean \pm S.E.M. of 5 animals. A best-fit line to the effect compartment model is shown. Some of the data were derived from Ref. 9.

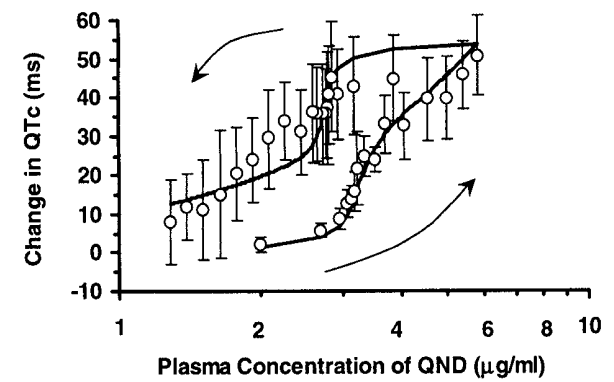

Fig. 8. Relationship between the Change in QTc Interval and the Plasma QND Concentration in Guinea Pigs

Data are expressed as the mean \pm S.E.M. of 5 animals. Each arrow indicates an elapse of time. A best-fit line to the effect compartment model is shown. Some of the data were derived from Ref. 9. 
Table 2. Pharmacodynamic Parameters of FK506 and QND

\begin{tabular}{llcc}
\hline \multicolumn{2}{c}{ Parameters } & FK506 & QND \\
\hline$k_{\mathrm{E} 0}$ & $\left(\mathrm{~min}^{-1}\right)$ & $2.72 \times 10^{-4}\left[1.66 \times 10^{-4}, 7.48 \times 10^{-4}\right]$ & $0.148[0.126,0.170]$ \\
$E_{\max }(\mathrm{ms})$ & $27.1[25.8,28.4]$ & - \\
$E C_{50}$ & $(\mathrm{ng} / \mathrm{ml})$ & $0.376[0.289,0.489]$ & - \\
$K$ & $(\mathrm{~ms} \cdot \mathrm{ml} / \mu \mathrm{g})$ & - & $8.41[8.04,8.79]$ \\
\hline
\end{tabular}

See text for abbreviations. The parameters were derived using an effect compartment model. Values are expressed as the estimate [ $68 \%$ confidence interval].

contrast to FK506, QND administration resulted in a QTc interval that returned to basal levels $150 \mathrm{~min}$ after termination of the infusion (Fig. 7). The relationship between plasma concentration of QND and the change in QTc interval after infusion also showed an anti-clockwise hysteresis (Fig. 8).

PK/PD Analysis of QT Prolongation The pharmacodynamic parameters are presented in Table 2 . It can be seen that the $k_{\mathrm{E} 0}$ value for FK506 is far lower than that for QND. The best-fit lines in Figs. 5-8 were generated using the effect compartment model.

\section{DISCUSSION}

In this study, the effect of FK506 on the QT interval was investigated in guinea pigs in a quantitative manner, since QT prolongation associated with FK506 has been reported clinically $^{7,8)}$ and experimentally. ${ }^{9)}$

A delay of QT prolongation with respect to plasma concentration was observed for both FK506 and QND. Therefore, the effect compartment mode ${ }^{15)}$ was applied to analyze the relationship between the plasma concentrations of these drugs and QT prolongation. Although the $k_{\mathrm{E} 0}$ value for FK506 appears to exceed the range of values for the parameters that could feasibly be determined under the present time scale, the QT prolonging effect of FK506 clearly persisted for at least $4 \mathrm{~h}$. In any event, it is of note that the QT prolongation induced by FK506 persisted for much longer than that induced by QND. Selection of an appropriate procedure for the modeling of PK/PD data should, if possible, be based on the mechanism by which a drug induces its response. However, the effect compartment model is applicable not only to a drug which is slow to transfer to its effect site but also to a drug with an active metabolite (e.g. QND ${ }^{15,25)}$ ), or with an indirect response. In this regard, the effect compartment model is a general and practical model for analyzing the PK/PD relationship to anti-clockwise hysteresis. Whereas the delay of QND-induced QT prolongation is known to be due to the effects of its metabolites, ${ }^{15,25-29)}$ that of FK506 remains open to question. ${ }^{9)}$ Therefore, we employed the effect compartment model to analyze the PK/PD of FK506- and QND-induced QT prolongation rather than using mechanism-based models such as an active metabolite model $^{30)}$ or an indirect response model. ${ }^{31-33)}$

QND induced significant QTc prolongation in guinea pigs at a plasma concentration range of $3-7 \mu \mathrm{g} / \mathrm{ml}$, which corresponds with the therapeutic range. This result agrees well with the high arrhythmogenic activity of QND observed clinically. In comparison, the therapeutic range of FK506 is 5$20 \mathrm{ng} / \mathrm{ml},{ }^{34,35)}$ when measured as whole blood trough concentration. Since the blood-to-plasma concentration ratios of FK506 in human and guinea pigs were almost equal, as evidenced by this study and that of Nagase et al. ${ }^{18)}$ (Fig. 2), we estimated that the therapeutic plasma concentration of FK506 was $0.154-0.654 \mathrm{ng} / \mathrm{ml}$ at an $\mathrm{Ht}$ of 0.452 , using Eq. 1. However, in some clinical cases of transplantation, the $H t$ is usually reduced to 0.2 to decrease the viscosity of blood. ${ }^{36}$ ) In such a case, an FK506 concentration of $5-20 \mathrm{ng} / \mathrm{ml}$ whole blood would give a plasma concentration of 0.343 $1.56 \mathrm{ng} / \mathrm{ml}$, at which concentration significant QTc prolongation was observed in the current study. Therefore, we propose that FK506 might induce QT prolongation within its therapeutic range in clinical use. It is of note that blood distribution property and $H t$ should be important physiological factors in predicting the PK/PD of FK506, as well as in predicting that of cyclosporine $A \cdot{ }^{37-40)}$

It is desirable to directly determine the plasma concentration of FK506, since the plasma concentration is likely to relate more directly to the effects of FK506 than the whole blood concentration. In the present in vivo study, the plasma concentration of FK506 was simulated from the whole blood concentration by means of the in vitro blood-to-plasma concentration ratio and 3-compartment model above. In humans, ${ }^{18)}$ rats ${ }^{19)}$ and rabbits, ${ }^{20,21)}$ the distribution of FK506 into blood cells is extensive and saturable and the present study showed that the drug also exhibited a similar property in guinea pigs (Fig. 2). However, the distribution of FK506 into blood cells is reported to be temperature-dependent. ${ }^{41)}$ In clinical settings, whole blood concentrations of FK506 are used for therapeutic drug monitoring, ${ }^{34)}$ and a small sample volume is sufficient for monitoring whole blood concentration. For these reasons, monitoring whole blood concentrations appears far more advantageous and practical than monitoring plasma concentrations.

In conclusion, FK506-induced QTc prolongation, which we previously reported for the first time in guinea pigs, ${ }^{9)}$ was successfully analyzed using the effect compartment model. Plasma concentrations of the drug, which are more relevant than whole blood concentrations for investigating such pharmacological effects as adverse reactions, were employed for pharmacokinetically meaningful comparison between guinea pigs and humans. The present model may provide a rational basis for developing clinical strategies to avoid possible QT prolongation resulting from either an overdose of FK506, metabolic inhibition by a concomitantly administered drug, or decreases in $\mathrm{Ht}$. Further study is required in order to fully elucidate the mechanism by which FK506 induces QT prolongation.

\section{REFERENCES}

1) Denton M. D., Magee C. C., Sayegh M. H., Lancet, 353, 1083-1091 (1999).

2) Okudaira H., Mori A., Int. Arch. Allergy Immunol, 117, 11-19 (1998).

3) Japanese FK506 Study Group, Transplant. Proc., 23, 3071-3074 (1991).

4) Atokison P., Joubert G., Barron A., Grant D., Paradis K., Seidman E., Wall W., Rosenberg H., Howard J., Williams S., Stiller C., Lancet, 345, 894-896 (1995)

5) Cox T. H., Baillie G. M., Baliga P., Pharmacotherapy, 17, 1328-1330 (1997).

6) Sawabe.T., Mizuno S., Gondo H., Maruyama T., Niho Y., Transplantation, 64, 182-183 (1997).

7) Johnson M. C., So S., Marsh J. W., Murphy A. M., Transplantation, 53, 929-930 (1992).

8) Hodak S. P., Moubarak J. B., Rodoriguez I., Gelfand M. C., Alijani M. 
R., Tracy C. M., Transplantation, 66, 535-537 (1998).

9) Minematsu T., Ohtani H., Sato H., Iga T., Life Sci., 65, PL197-_PL202 (1999).

10) Ohtani H., Hanada E., Yamamoto K., Sawada Y., Iga T., Biol. Pharm. Bull., 19, 1189-1196 (1996).

11) Ohtani H., Hanada E., Sawada Y., Iga T., J. Pharm. Pharmacol., 49, 458-462 (1997).

12) Hirota M., Ohtani H., Hanada E., Kotaki H., Sawada Y., Iga T., Life Sci., 62, 2159-2169 (1998).

13) Hanada E., Ohtani H., Kotaki H., Sawada Y., Sato H., Iga T., J. Pharm. Sci., 88, $234-240$ (1999).

14) Ohtani H., Sato H., Iga T., Kotaki H., Sawada Y., Biopharm. Drug Dispos., 20, 101-106 (1999).

15) Holford N. H. G., Sheiner L. B., Clin. Pharmacokin., 25, 358-453 (1979).

16) Kay G. N., Plumb V. J., Arciniegas J. G., Henthorn R. W., Waldo A. L., J. Am. Coll. Cardiol., 2, 816-817 (1983).

17) Venkataramanan R., Swaminathan A., Prasad T., Jain A., Zuckerman S., Warty V., McMichael J., Lever J., Burckart G., Starzl T., Clin. Pharmacokin., 29, 404-430 (1995).

18) Nagase K., Iwasaki K., Shiraga T., Nozaki K., Noda K., J. Pharm. Pharmacol., 46, 113-117 (1993).

19) Iwasaki K., Shiraga T., Nagase K., Hirano K., Nozaki K., Noda K., Transplant. Proc., 23, 2757-2759 (1991).

20) Piekoszewski W, Chow F. S., Jusko W. J., Drug Metabol. Dispos., 21, 690-698 (1993).

21) Chow F. S., Piekoszewski W., Jusko W. J., Drug Metabol. Dispos., 25, 610-616(1997)

22) Yamaoka K., Tanigawa Y., Nakagawa T., Uno T., J. PharmacobioDyn., 4, 879-885 (1981).

23) Bazett H. C., Heart, 7, 353-370 (1920).

24) Hayes E., Pugsley M. K., Penz W. P., Adaikan G., Walker M. J., J. Pharmacol. Toxicol. Methods, 32, 201-207 (1994).

25) Holford N. H. G., Coates P. E., Guentert T. W., Riegelman S., Sheiner L. B., Br. J. Clin. Pharmacol., 11, 187-195 (1981).
26) Vozeh S., Uematsu T., Guentert T. W., Ha H. R., Follath F., Clin. Pharmacol. Ther, 37, 575-581 (1985).

27) Vozeh S., Bindschedler M., Ha H. R., Kaufmann G., Guentert T. W., Follath F., Am. J. Cardiol., 59, 681-684 (1987).

28) Uematsu T., Vozeh S., Ha H. R., Follath F., Nakashima M., J. Pharmacol. Methods, 18, 179-185 (1987).

29) Uematsu. T., Sato R., Vozeh S., Follath F., Nakashima M., Arch. Int. Pharmacodyn., 297, 29-38 (1989).

30) Tuk B., Van Oostenbruggen M. F., Herben V. M. M., Mandema J. W., Danhof M., J. Pharmacol. Exp. Ther, 289, 1067-1074 (1999).

31) Sharma A., Jusko W. J., J. Pharmacokin. Biopharm., 24, 611-635 (1996).

32) Krzyzanski W., Jusko W. J., J. Pharmacokin. Biopharm., 25, 107-123 (1997).

33) Derendorf H., Meibohm B., Pharm. Res., 16, 176-185 (1999).

34) Jusko W. J., Thomson A. W., Fung J., McMaster P., Wong S. H., Zylber-Katz E., Christians U., Winkler M., Fitzsimmons W. E., Lieberman R., McBride J., Kobayashi M., Warty V., Soldin S. J., Ther. Drug Monit., 17, 606-614 (1995).

35) Sewing K. F., Transplant. Proc., 26, 3267-3269 (1994).

36) Harihara Y., Makuuchi M., Jpn. J. Pediatr., 50, 2541-2550 (1997).

37) Shibata N., Hoshino N., minouchi T., Yamaji A., Park K., Tomoyoshi T., Abe H., Kodama M., Int. J. Clin. Pharmacol. Ther., 36, 202-209 (1998).

38) Shibata N., Hoshino N., Yamaji A., Park K. I., Inoue H., Tomoyoshi T., Sako H., Abe H., Kodama M., Nakane Y., Transplant. Proc., 28, $1313-1315$ (1996).

39) Shibata N., Minouchi T., Yamaji A., Park K. I., Inoue H., Tomoyoshi T., Sako H., Abe H., Kodama M., Nakane Y., Biol. Pharm. Bull., 18, 115-121 (1995).

40) Shibata N., Yamaji A., Park K. I., Tomoyoshi T., Sako H., Abe H., Kodama M., Nakane Y., Hodohara K., Hosoda S., Biol. Pharm. Bull., 17, 709-714 (1994).

41) Machida M., Takahata S., Ishibashi M., Hayashi M., Sekihara T., Yamanaka H., Transplant. Proc., 23, 2753-2754 (1991). 